\title{
An Empirical Study on Improving Residents Satisfaction of Basic Medical Insurance by Energy Saving and Efficiency Increasing
}

\author{
Zhang Ruihong ${ }^{1,2}$ \\ ${ }^{1}$ Business School, Henan Normal University, Xinxiang Henan 453007 \\ ${ }^{2}$ School of Labor Economics, Capital University of Economics and Trade, Beijing 100070
}

\begin{abstract}
In the new era, energy-saving and efficiency-increasing become the key to improve the satisfaction of residents' health insurance and strengthen the function of social security. With the implementation of China's resident medical insurance system, the problem of "difficult and expensive to see a doctor" has been alleviated to a certain extent, but the problems of management, supervision and management, which affect the sustainable and efficient operation of basic medical insurance, are still prominent, based on the microsurvey data, the evaluation index system of satisfaction degree of basic medical insurance is constructed, and the performance of residents' medical insurance is comprehensively evaluated by multiple linear regression method.
\end{abstract}

\section{Introduction}

China attaches great importance to the issue of residents' health and medical security, and through continuous exploration and improvement of the medical security system, the responsibilities of residents' health security management in different departments have been continuously integrated and improved, it has basically achieved "six UNIFICATIONS" in coverage, fund-raising policy, security treatment, medical insurance catalogue, fixed-point management and fund management, and effectively enhanced its positive role in ensuring basic medical care and preventing poverty caused by diseases. According to the latest statistics from the State Medical Security Bureau, by the end of 2020, the number of people participating in medical insurance in China was 1.017 billion, which basically achieved the system goal of "wide coverage and basic insurance coverage, " with significant increases in per capita funding and total funding, the fluctuation of treatment payment is rising, the fund balance and the ratio of fund balance are decreasing day by day, and the social security function of residents' medical insurance is strengthening day by day.

At the same time, the system itself, the operation mechanism and the guarantee effect and so on still have many key problems which restrict the guarantee effect. The report of the 19th National Congress of the Communist Party of China clearly points out that a multilevel social security system covering the whole people, urban and rural areas, with clear powers and responsibilities, appropriate security and sustainable security, should be built in an all-round way in accordance with the requirements of drawing the bottom line, weaving dense nets and establishing mechanisms, it indicates that our country has entered a new period of high-quality development of medical insurance and the complete establishment of the medical insurance system with Chinese characteristics. ${ }^{[1]}$

\section{Methodology}

\subsection{Data sources}

Because of the adjustment of medical insurance, it is difficult to get the data of medical insurance and lack of continuity. Therefore, we choose the way of on-the-spot investigation to analyze the satisfaction of residents. From October to December 2019, the survey was conducted mainly through questionnaires and interviews, with the respondents filling in the questionnaires on their own. For those who could not fill in the questionnaires due to their age, educational level and other reasons, the respondents responded in the form of questions and answers instead of answers, fully ensure that the questionnaire is the true attitude of the respondents. A total of 500 questionnaires were distributed and 450 questionnaires were collected, of which 420 were valid. The effective recovery rate was $93.33 \%$.

\subsection{Descriptive analysis}

See Table 1, through the payment and treatment of medical insurance, edical and management services, such as the specific content of the survey, statistical residents on the overall health insurance in a relatively satisfactory state. The average level of residents' satisfaction with the payment and treatment of the system is the highest at $47.18 \%$. The satisfaction degree of fixed-point medical institutions was in the middle of general satisfaction and 
relative satisfaction, accounting for $44.25 \%$ and $29.85 \%$

insurance agency was $41.79 \%$.

respectively. The most satisfactory rate of the medical

Table 1. Health care satisfaction of residents (\%)

\begin{tabular}{|c|c|c|c|c|c|}
\hline Projects & $\begin{array}{c}\text { Very } \\
\text { Dissatisfied }\end{array}$ & Not Satisfied & Neutral & Satisfied & $\begin{array}{c}\text { Very } \\
\text { Satisfied }\end{array}$ \\
\hline Payment and treatment & 5.47 & 24.48 & 47.18 & 17.23 & 5.64 \\
\hline $\begin{array}{c}\text { Medical institutions and } \\
\text { services }\end{array}$ & 2.90 & 13.53 & 44.25 & 29.85 & 9.47 \\
\hline $\begin{array}{c}\text { Operating agencies and } \\
\text { services }\end{array}$ & 0.36 & 6.52 & 33.36 & 41.79 & 18.24 \\
\hline
\end{tabular}

\subsection{Regression analysis}

The selection of independent and dependent variables is shown in Table 2.

\subsubsection{Variable selection}

Table 2. Independent variable and variable selection and definition

\begin{tabular}{|c|c|c|}
\hline \multicolumn{2}{|r|}{ Independent Variable } & Dependent Variable \\
\hline \multirow{11}{*}{$\begin{array}{c}\text { Residents' } \\
\text { satisfaction (Y) }\end{array}$} & \multirow{3}{*}{ Payment and treatment $\left(\mathrm{Y}_{1}\right)$} & Individual contribution $\left(\mathrm{X}_{1}\right)$ \\
\hline & & Reimbursement rate $\left(\mathrm{X}_{2}\right)$ \\
\hline & & Scope of reimbursement $\left(\mathrm{X}_{3}\right)$ \\
\hline & \multirow{4}{*}{ Medical institutions and services $\left(\mathrm{Y}_{2}\right)$} & Medical standard $\left(\mathrm{X}_{5}\right)$ \\
\hline & & Charge level $\left(\mathrm{X}_{6}\right)$ \\
\hline & & Medical conditions $\left(\mathrm{X}_{7}\right)$ \\
\hline & & Service attitude $\left(\mathrm{X}_{8}\right)$ \\
\hline & \multirow{4}{*}{ Operating agencies and services $\left(\mathrm{Y}_{3}\right)$} & Reimbursement procedures $\left(\mathrm{X}_{9}\right)$ \\
\hline & & Policy advocacy $\left(\mathrm{X}_{10}\right)$ \\
\hline & & Ability $\left(\mathrm{X}_{11}\right)$ \\
\hline & & Service attitude $\left(X_{12}\right)$ \\
\hline
\end{tabular}

\subsection{2 model setting and Regression analysis}

Using SPSS software to analyze the Regression analysis of residents' satisfaction with health insurance. The regression analysis results are as follows:

$$
Y_{I}=0.286 * X_{I}+0.284 * X_{2}+0.264 * X_{3}+0.613
$$

As shown in Table 3:

$$
\begin{gathered}
Y 2=0.189 * X_{4}+0.124 * X_{5}+0.307 * X_{6}+ \\
0.121 * X_{7}+0.190 * X_{8}+0.274 \\
Y_{3}=0.101 * X_{9}+0.267 * X_{10}+0.277 * X_{11}+ \\
0.278 * X_{12}+0.290
\end{gathered}
$$

Then we use SPSS software to analyze the Regression

\begin{tabular}{|c|c|c|c|c|c|c|}
\hline & \multicolumn{2}{|c|}{$\begin{array}{c}\text { Nonstandard } \\
\text { Coefficient }\end{array}$} & \multirow{2}{*}{$\begin{array}{c}\begin{array}{c}\text { Standard } \\
\text { Coefficient }\end{array} \\
\text { Beta }\end{array}$} & \multirow[t]{2}{*}{$\mathbf{t}$} & \multirow[t]{2}{*}{$\mathbf{p}$} & \multirow[t]{2}{*}{ VIF } \\
\hline & B & $\begin{array}{c}\text { Standard } \\
\text { Error }\end{array}$ & & & & \\
\hline Constant & 0.352 & 0.140 & - & 2.507 & $0.013 * *$ & \\
\hline Payment and treatment & 0.308 & 0.044 & 0.328 & 7.067 & $0.000 * *$ & 1.587 \\
\hline $\begin{array}{c}\text { Medical institutions and } \\
\text { services }\end{array}$ & 0.217 & 0.047 & 0.242 & 4.588 & $0.000 * *$ & 2.045 \\
\hline $\begin{array}{c}\text { Operating agencies and } \\
\text { services }\end{array}$ & 0.411 & 0.041 & 0.459 & 10.028 & $0.000 * *$ & 1.545 \\
\hline $\begin{array}{l}\mathrm{R}^{2}: 0.725 \\
* \mathrm{p}<0.05 * * \mathrm{p}\end{array}$ & $\begin{array}{l}\text { djusti } \\
01\end{array}$ & 0.721 & 164 & $\mathrm{D}-\mathrm{W}$ & 2.003 & \\
\hline
\end{tabular}
analysis of three dimensions. The regression analysis results are as follows:

$$
Y=0.308 * Y 1+0.217 * Y 2+0.411 * Y 3+0.352
$$

Table 3. Multivariate linear regression results of residents' overall satisfaction with health insurance

As can be seen from the above table, R' squared is 0.725. Health Insurance Policy, medical institutions and agencies and services are the key factors that affect the overall satisfaction, accounting for $72.5 \%$. The $\mathrm{F}$ test of the model shows that $\mathrm{f}=178.164, \mathrm{p}=0.000$, which shows that it is meaningful to construct the model. The regression 
coefficients of system payment and treatment, medical institution and Management Institution and service are $0.308,0.217,0.411$ respectively. All the above three factors have significant positive correlation with the overall satisfaction of residents' medical insurance.

\section{Conclusions and recommendations}

\subsection{Basic conclusion}

By means of inductive analysis, the following basic conclusions can be drawn: (1) Residents are generally satisfied with the health insurance system, which shows that after many years of reform and exploration, the effectiveness of the health insurance system has obviously improved, but there is still room for further adjustment and improvement,(2) The satisfaction degree still has the big promotion space, indicated that realizes the system coordinated development to shoulder heavy responsibilities,(3) There is a great difference in the satisfaction degree between the regions as a whole, and the regions with better economic development are obviously higher than those with General Economic Development.

For this reason, with the development of economy and society and the rising expectation of residents for the efficiency of the security system, it is urgent to promote and improve the design of the system, improve related supporting policies, and encourage the coordinated development of various regions, etc. provide strong support for the system.

\subsection{Optimization recommendations}

\subsubsection{Improving top level design}

Take a step-by-step approach to achieve the standardization and improvement of the institutional framework. The reform and adjustment of the system needs a wide range of words. Specifically, through the effective information communication, transmission and feedback mechanism, the participation of the public can be improved. With the help of people from all walks of life to make suggestions and suggestions for the optimization of the system, and through the practice of pilot reforms and incremental adjustments. To explore the establishment of an institutional framework for coordinated development with the economy and society. ${ }^{[2]}$

Continuously optimize and improve the quality and efficiency of the system. Clearly define the objectives of the system and financing mechanisms, truly through mutual assistance, to protect people's basic medical rights and interests. Through gradual reform, we can adopt a financing mechanism that is directly linked to the income level, with payment fixed, pay-as-you-go and standardized. In particular, we will use the actuarial balance method to flexibly adjust individual payment standards and scientifically determine the treatment of the system, and establish an overall coordination mechanism to gradually reduce the treatment gap between the regions. [3]

\subsubsection{Improvement of system management and operational efficiency}

Straighten out and optimize the management mechanism of basic medical insurance, release the management efficiency effectively. First, we can learn from Germany, the Netherlands, the United States and other countries, innovate the supply mechanism, through the introduction of the competition mechanism, allow all kinds of medical institutions to participate in fair competition, and form a healthy and orderly supply of resources, then realizes each main body to the system stable anticipation. Secondly, strengthen the supervision of medical service institutions, drug distribution and prices, standardize and improve the system of evaluation and supervision, and unify the drug catalogue of hospitals at all levels on the premise of ensuring that the payment burden does not increase, it also has the flexibility to adjust the scope of the catalogue so as to ensure that residents enjoy relatively equal protection treatment. Thirdly, with the help of the Internet and modern technology, a scientific and standardized information system can be set up to monitor and track the whole process of the relevant actors in real time, and to provide automatic early warning for the management of inefficient and wasted resources and medical behaviors, and to standardize and strengthen the system of medical information disclosure to eliminate the problem of rising costs caused by Information asymmetry.

Improve and enhance the system service quality, effective release system operating efficiency. On the one hand, through the establishment of Intelligent Information System Platform, the management service process is optimized, and the precise and personalized service is provided according to the situation of each region. On the other hand, we can learn from the practice of serious diseases medical insurance in some regions, in order to make use of the professional risk management technology of the Insurance Company and promote the sustainable and effective operation of the system, the management of Insurance Company is introduced through open market competition. At the same time, in order to respect and protect the basic rights and interests of the insured, we can establish an evaluation system for the management services, including the third party, and adjust the management personnel and organizations according to the evaluation results, so that the management units truly aim at providing high-quality services. ${ }^{[4]}$

\subsubsection{Improve relevant supporting policies}

In the face of the deepening of the population ageing, the payment pressure of the basic medical insurance system is increasing. The current payment model can be reformed and the principle of reciprocity of rights and obligations can be followed. At the same time, taking the opportunity of the implementation of the "healthy China strategy" put forward in the report of the 19th National Congress of the $\mathrm{CPC}$ as an opportunity, continue to deepen the reform of the medical and health system, actively carry out nationwide fitness activities, advocate healthy lifestyle, and realize the improvement of the health level of the whole people, effectively mitigate the payment risk of the 
medical insurance system.

\subsection{4 coordinated development of incentive and exploratory systems}

It is found that the eastern region with better economic development is better than the western region in the aspects of operation, management and supervision of the medical insurance system. Therefore, by actively drawing on the experience of the development of advanced regions and guiding the practice of adjusting and optimizing the operation of the system according to local conditions such as economy, population and income, so as to promote the coordinated development of the economy, society and guarantee efficiency, and bring it into the assessment system of the local government. ${ }^{[5]}$

\section{Author}

${ }^{*}$ Corresponding author:1, 2 Zhang Ruihong, associate professor, Henan Normal University, phd candidate, School of Labor Economics, Capital University of Economics and Trade. No. 46 East Jianshe Road, Xinxiang, Henan, 453007.

zhangruii34510@126.com.

\section{References}

1. Y. L Qiu, Z.Q, Wang, Forty years development of Chinese Medical Insurance System: process, experience and prospect. C. C. N. U 1, 23-30(2019).

2. E.Ostrom, X.D Yu, X.D Chen, The Governance of Public Things -- The Evolution of Collective Action System.S.T.P.H (2000).

3. W.J He, Social Security in China: from rapid expansion to high-quality development. C.P.S 1, 2-15 (2019):

4. C.H Li et al. The revelation of American medical insurance contractor management to China's Basic Medical Insurance Management. C.H.E 12, 113-116 (2018).

5. C.Q. Wang, Integration of Basic Medical Insurance System for urban and rural residents: a policy comparison based on 28 provinces. M. T 11, 83-92 (2018). 